\title{
Disentangling the effects of thematic information and emphasis frames and the suppression of issue-specific argument effects through value-resonant framing
}

\author{
Kaiser, Johannes
}

\begin{abstract}
Research on emphasis framing effects has recently received important criticism. Most of this critique argues that emphasis frames that make a specific aspect of an issue more salient are often confounded with the additional presentation of new thematic information. This could imply that citizens' susceptibility to emphasis framing effects is overstated, as these effects could also originate from new issue-specific facts and arguments contained in the different frames and not from the mere emphasis on certain frames. Using a representative sample $(\mathrm{N}=833)$, this study conducts a $2 \times 3 \times 2$ online experiment separating the effects of the persuasiveness of new thematic information (i.e., of issue-specific argument strength) and of salience emphasis frames to test the effects of each depending on citizens' political value preferences. These salience emphasis frames employ cross-thematic political values that citizens already know and are thus not confounded with the provision of new thematic information. Results show that issue-specific argument strength (i.e., the new facts about an issue) exerts effects on issue attitudes. However, salience emphasis frames also show clear effects. The framing effect is present regardless of both issue-specific argument strength the frame contextualizes and of citizens' political values. Moreover, value-resonant frames matching citizens' preferences suppress the effects of new thematic information. This not only implies that emphasis frames can be effective without providing new substantive information but also that citizens rely more on the salience of emphasis frames than on the argument strength of thematic information, questioning the quality of citizens' attitude formation under framing conditions.
\end{abstract}

DOI: https://doi.org/10.1080/10584609.2019.1658662

Posted at the Zurich Open Repository and Archive, University of Zurich

ZORA URL: https://doi.org/10.5167/uzh-174878

Journal Article

Accepted Version

Originally published at:

Kaiser, Johannes (2020). Disentangling the effects of thematic information and emphasis frames and the suppression of issue-specific argument effects through value-resonant framing. Political Communication, 37(1):1-19. DOI: https://doi.org/10.1080/10584609.2019.1658662 
This is the full-text of the accepted version of the paper:

Kaiser, J. (2019). Disentangling the effects of thematic information and emphasis frames and the suppression of issue-specific argument effects through value-resonant framing. Political Communication, 1-19. https://doi.org/10.1080/10584609.2019.1658662

\title{
Disentangling the effects of thematic information and emphasis frames and the suppression of issue-specific argument effects through value-resonant framing
}

\begin{abstract}
Research on emphasis framing effects has recently received important criticism. Most of this critique argues that emphasis frames that make a specific aspect of an issue more salient are often confounded with the additional presentation of new thematic information. This could imply that citizens' susceptibility to emphasis framing effects is overstated, as these effects could also originate from new issue-specific facts and arguments contained in the different frames and not from the mere emphasis on certain frames. Using a representative sample $(\mathrm{N}=833)$, this study conducts a $2 \times 3 \times 2$ online experiment separating the effects of the persuasiveness of new thematic information (i.e., of issue-specific argument strength) and of salience emphasis frames to test the effects of each depending on citizens' political value preferences. These salience emphasis frames employ cross-thematic political values that citizens already know and are thus not confounded with the provision of new thematic information. Results show that issue-specific argument strength (i.e., the new facts about an issue) exerts effects on issue attitudes. However, salience emphasis frames also show clear effects. The framing effect is present regardless of both issue-specific argument strength the frame contextualizes and of citizens' political values. Moreover, value-resonant frames matching citizens' preferences suppress the effects of new thematic information. This not only implies that emphasis frames can be effective without providing new substantive information but also that citizens rely more on the salience of emphasis frames than on the argument strength of thematic information, questioning the quality of citizens' attitude formation under framing conditions.

Keywords: framing effects, political values, attitude formation, motivated reasoning, political communication effects
\end{abstract}


For decades, political communication research has debated the question of how susceptible citizens react to communication that aims to change their political attitudes (Neuman \& Guggenheim, 2011). Various kinds of communication have been analyzed to understand their effectiveness, but less has received more attention than the investigation of emphasis framing effects (Scheufele \& Iyengar, 2017). Emphasis frames, also referred to as issue frames in academic literature (Nelson, Oxley, \& Clawson, 1997; Slothuus, 2008), focus on "a subset of potentially relevant considerations" when describing a (political) issue or event (Druckman, 2001, p. 230). When a political actor speaks about offshore oil drilling, for example, the actor can use different emphasis frames highlighting a specific perspective of the issue to define and construct a certain meaning for the audience (Entman, 1993), such as an economic frame focusing on the financial benefits of drilling or an environmental frame emphasizing the negative outcomes for the environment (Druckman, Peterson, \& Slothuus, 2013).

Numerous studies have shown that emphasis frames can influence citizens' issue attitudes regarding a wide range of political topics such as the enlargement of the European Union (Lecheler \& de Vreese, 2011, 2013), new technologies (Druckman \& Bolsen, 2011), health conditions (Matthes \& Schemer, 2012), social welfare (Slothuus, 2008), energy and immigration policies (Druckman et al., 2013), urban growth projects, and hate group rallies (Chong \& Druckman, 2007a). In particular, the construction of emphasis frames through the use of political values (i.e., value framing) is not only an often employed strategy by political actors (Hänggli \& Kriesi, 2010) but it also seems to be an effective tool to influence citizens' attitudes (Beattie \& Milojevich, 2017; Schemer, Wirth, \& Matthes, 2012; Shen \& Edwards, 2005).

However, studies on emphasis framing effects have received significant criticism over the past years (e.g., Cacciatore, Scheufele, \& Iyengar, 2016) arguing that many of the deployed 
frames in effects research are confounded with varying new thematic information, i.e., with the provision of new issue-specific facts and arguments in the emphasis frames (Leeper \& Slothuus, 2017). It is therefore possible that past research overrated the effectiveness of emphasis frames for attitude formation that could also originate from a simple effect of differing new thematic information contained in the varying frames (Leeper \& Slothuus, 2017; Scheufele \& Iyengar, 2017). Hence, this experimental study will respond to this critique by clearly disentangling the effects of new issue-specific information and of non-confounded emphasis frames by introducing the concept of salience emphasis frames that do not provide any new thematic information when framing an issue. This will enable a test of whether emphasis frames have any unique attitudinal effects, which is important for the theoretical survivability of the emphasis framing approach.

In addition, the separation of salience emphasis frames and new issue-specific information into two independent variables allows answering a follow-up question that is relevant for assessing the quality of public opinion formation under framing conditions that confounded studies on emphasis framing cannot test: Do salience emphasis frames only slightly change the perceptions of identical thematic information? Or are such frame effects so strong that differences in the persuasiveness of new facts contained in thematic information (i.e., issuespecific argument strength) no longer matter, even though these differences in issue-specific argument strength would matter without a salience emphasis frame? This change is worth investigating as it would imply that such frames can compromise a fact-based attitude formation.

\section{Disentangling the effects of new thematic information and salience emphasis frames}

Leeper and Slothuus (2017) reviewed more than 100 studies on emphasis framing effects concerned with political topics. Their analysis revealed that nearly all of the employed stimuli confounded the emphasis through frames with varying new thematic information in these frames. 
For example: the frame of civil rights contains additional information on the topic of a new surveillance law, such as every citizen can be surveilled through the new law without a reasonable suspicion. This new issue-specific information is not mentioned in the safety frame condition, whereas the safety frame adds new thematic information about how many criminal acts the law will prevent. The authors conclude that this confounding is a mismatch between theory that defines persuasive argument effects based on the offering of new information and framing as the emphasis on how this information should be weighted (see also Nelson et al., 1997) and empirical studies that confounded both (for a comparable argument, see also Scheufele \& Iyengar, 2017). Moreover, this confounding could imply that the susceptibility to the effects of issue frame emphases is overrated in the literature (Leeper \& Slothuus, 2017).

When looking at the classic definition of emphasis framing by Entman (1993), however, "To frame is to select [emphasis added] some aspects of a perceived reality and make them more salient [emphasis added] in a communicating text, in such a way to promote a particular problem definition, causal interpretation, moral evaluation and/or treatment recommendation" (p. 52), it seems at a first glance that theory allows for the construction of emphasis frames with both, the selection of new thematic information (e.g., a new infrastructure project will lead to 1,000 new jobs) and the salience of the frame (e.g., it is important to evaluate the new infrastructure project in light of the creation of new jobs). According to this definition, a political actor could also construct an emphasis frame by selecting new factual arguments (i.e., selection emphasis framing) and not only by suggesting an interpretation of a given situation within a certain frame but without adding new thematic information (i.e., salience emphasis framing).

However, while Entman's definition helped unifying the psychological and sociological roots of framing, thereby inspiring hundreds of excellent studies in the field of political 
communication, his definition of emphasis framing has the downside that at least emphasis frames that select and present new thematic information can no longer be distinguished on the theoretical level from persuasion through new information. This critique is shared by Cacciatore et al. (2016) who have criticized that the emphasis framing approach has turned into a "catch-all phrase for a number of distinct media effects models" (p. 20) blurring the theoretically important differentiation between framing, persuasion based on the provision of new information, and other types of communicative influences.

In order to secure the theoretical survivability of the framing approach, Cacciatore et al. (2016) opt for a more narrow definition of framing that employs equivalency frames instead of confounded emphasis frames (see also Scheufele \& Iyengar, 2017). Equivalency frames do not contain any additional information but use "different, but logically equivalent, words or phrases" (Druckman, 2001, p. 228) to frame the same issue-specific information (e.g., $95 \%$ employment vs. $5 \%$ unemployment). While this concept clearly solves the problem of not confounding the frame with new thematic information, it further expects that not only the thematic information is logically equivalent but also the frames themselves, which would limit the emphasis framing approach to a small set of externally valid situations of real communication processes (Slothuus, 2008). Often-employed frames by political actors, such as civil rights or national security, are not logically equivalent frames even if they would frame the same thematic information. That is, such frames would become a blind spot if research would only focus on equivalency framing.

Hence, I propose the slightly different definition of salience emphasis frames that are like equivalency frames - not confounded with the provision of new issue-specific information but allow for logical differences between already known emphasis frames applied to the same (i.e., logically equivalent) new thematic information that is framed. This concept follows Leeper 
and Slothuus (2017) who also separated the effects of thematic information and emphasis frames. However, the authors operationalized the frames by simply stating after the stimulus that some people judged the information "based on whether it [is costly | will affect the health of average Americans]" (p. 22), whereas the thematic information in the stimulus was presented far more extensively, which might explain why they did not find substantial effects of emphasis frames.

In contrast, I understand salience emphasis framing as a broader and explicit contextualization of new thematic information that is not necessarily limited to a half sentence but explains with cross-thematic patterns of interpretation that citizens already know what new thematic information means and how it should be interpreted. When emphasizing a certain aspect of an issue, this must not necessarily be an issue-specific emphasis frame containing new thematic information. Some frames are cross-thematic and refer to superordinate principles of interpretation that already exist in citizens' minds (Kaiser \& Kleinen-von Königslöw, 2019) such as the general importance of economic growth or the protection of the environment. Salience emphasis frames employ such already known cross-thematic patterns of interpretation without adding any new factual information on the specific topic, thereby not altering the amount of information that is potentially available for citizens to interpret the issue. The frame only alters the salience of this familiar pattern of cross-thematic information and establishes a connection of this pattern with what is framed (i.e., with the new issue-specific information in a message).

I propose that value frames can serve as such already known cross-thematic patterns of interpretation. Core political values, such as liberty, egalitarianism, civil rights, and safety, are defined as stable, abstract, and superordinate conceptions of desirable or undesirable goals concerned with humanity, society, and public affairs (Jacoby, 2006). These values are applicable to a wide range of political topics and can frame new issue-specific information by providing 
patterns of interpretation that must not necessarily work with the provision of new thematic information, as citizens already know and understand these patterns. For instance, the frame national security can be applied to very different topics such as state surveillance, protective tariffs, and foreign wars by simply stating the same well-known pattern of interpretation that national security is of high importance for ensuring the continued existence of a state.

The concept of salience emphasis frames does not only serve to theoretically distinguish the emphasis framing approach from both persuasion based on new thematic information and equivalency framing. It also allows to analyze whether framing can lead to unsubstantiated attitudinal shifts, which is important for assessing the normative consequences of framing effects. According to Tversky and Kahneman (1981) one can define rationality as the stability of attitudes when thematic information remains unchanged. For instance, when preferring policy A over policy B in the morning, it is rational to also prefer A over B in the evening when there has been no new information on these policies. However, it can be rational to prefer B over A in the evening if new information about these policies has been received in the meanwhile. Thus, effects of confounded emphasis frames that offer new information do not necessarily imply an unsubstantiated attitude formation (cf. Chong \& Druckman, 2007b; Druckman, 2001) as these effects can always be the result of learning from the new thematic facts. In contrast, salience emphasis frames enable a test of irrational attitude formation because the information does not change, solely the salience of already known cross-thematic information does. Continuing the example, if receiving a salience emphasis frame leads to preferring policy B over A in the evening while having preferred the opposite in the morning when this frame was already known, then citizens' rationality in attitude formation under framing conditions would be questioned. However, given the long tradition of research on persuasion, I first expect that new 
thematic information containing factual arguments of varying strengths will exert an independent effect on issue attitude. Strong arguments are perceived as more compelling to form a certain attitude direction because they provoke more positive thoughts and less counter-arguing than weak arguments (Petty \& Cacioppo, 1986). Numerous persuasion studies have shown that citizens base their attitude formation on the strength of newly presented arguments (e.g. Park, Levine, Kingsley Westerman, Orfgen, \& Foregger, 2007), according to the Elaboration Likelihood Model especially when processed carefully (Petty \& Cacioppo, 1986). Thus, in line with the findings of Leeper and Slothuus (2017), I predict that citizens' issue attitude will be influenced by the strength of the issue-specific argument contained in new thematic information:

H1: New thematic information with higher argument strength will move the attitude of citizens in its direction compared to issue-specific information with weak arguments.

However, I also assume that salience emphasis frames will influence issue attitudes even if they do not add further thematic information but contextualize this given information with a political value and suggest how to interpret it. Value frames activate pre-existing, available, accessible, and applicable considerations (Chong \& Druckman, 2007c) that are deeply rooted in society (Entman, 1993), that should influence how citizens weigh this new information (Nelson et al., 1997), and numerous studies have shown that value frames can finally affect issue attitudes (Beattie \& Milojevich, 2017; Chong \& Druckman, 2007a; Schemer et al., 2012; Shen $\&$ Edwards, 2005). Thus, the next hypotheses state that a salience emphasis frame employing a political value will significantly influence issue attitudes compared to situations without explicit framing but only with the new thematic information $(\mathrm{H} 2)$ and compared to a counter-frame using a different political value to contextualize the same new thematic information (H3):

H2: A salience emphasis frame will move the attitude of citizens in its direction 
compared to situations without explicit frames and only with new thematic information.

H3: A salience emphasis frame will move the attitude of citizens in its direction compared to situations with an opposite counter-frame based on the same thematic information.

I also vary the argument strength of the facts in the new thematic information (see H1) to investigate whether the effects of salience emphasis frames are present only when the argument strength of new issue-specific information is already favoring an attitude in accordance with the additionally applied frame, or whether frames can be likewise effective when the argument strength is weak, i.e., when the substantive information is against the direction of the frame. This would be an even stronger indicator for citizens' susceptibility to framing effects since it would mean that frames can be effective for weak facts. Thus, the first research question asks:

RQ1: Does the effect of the salience emphasis frame persist regardless of the argument strength of the new thematic information it contextualizes?

\section{The role of citizens' political value preferences as a moderator of emphasis framing effects}

An ongoing question in emphasis framing effects research is whether framing effects work uniformly or whether they are moderated by characteristics of citizens (Borah, 2011). When looking at value framing, an essential moderator is citizens' political value preferences (Andrews, Clawson, Gramig, \& Raymond, 2017; Schemer et al., 2012; Shen \& Edwards, 2005). Citizens adhere to political values in varying degrees and hold a hierarchical order of values, i.e., they have specific political value preferences (Jacoby, 2006). When forming attitudes about concrete political events, candidates, policies, or issues, citizens rely on their political value preferences which allow them to evaluate these topics under the umbrella of their core beliefs (Ciuk, Lupton, \& Thornton, 2017; Feldman, 1988; Jacoby, 2006). Thus, I first expect a general and independent main effect of political value preference when citizens form their issue attitude: 
H4: Citizens will differ in their issue attitude according to their political value preference.

However, value preferences not only affect directly the interpretation of issues, but they also influence how value frames in political messages are interpreted, i.e., they can moderate the effects of frames. If citizens hold values congruent to the frame, i.e., the communicated frame is value-resonant, framing effects tend to be stronger (Andrews et al., 2017; Schemer et al., 2012; Shen \& Edwards, 2005). If frames are value-resonant, they rely on considerations that are chronically accessible for the recipient, and therefore, a value-resonant frame can activate these existing cognitions more easily. This increases the likelihood that this frame will be used for attitude formation compared to a non-resonant frame which tries to activate considerations that are less chronically accessible (Schemer et al., 2012; Shen \& Edwards, 2005). In addition, the applicability of a frame is judged by the receiver based on her or his political value preferences. If the frame is value-resonant, it is perceived to be more in accordance with the person's values and is judged as more appropriate to evaluate the topic. This increases the likelihood that the attitude will follow this frame compared to a non-resonant frame (Andrews et al., 2017).

Nevertheless, this does not mean that frames exert effects only when they match preexisting value preferences. Value frames build on political core beliefs such as humanitarianism or safety that are not easily declinable even if they are not on top of individual value hierarchies. Such values are well known and in the stock of cultural frames (Entman, 1993). Thus, value frames use available and applicable considerations that fulfill an important precondition for the effectiveness of frames (Chong \& Druckman, 2007c). Some studies have already shown effects of value frames even for citizens holding competing preferences, in particular, when frames are one-sided (Beattie \& Milojevich, 2017), strong (Chong \& Druckman, 2007a), or presented in a non-polarized environment (Druckman et al., 2013). Hence, the second research question asks: 
RQ2: Does the effect of the salience emphasis frame persist regardless of whether the frame is value- resonant or not?

Even if such frames might work for citizens holding competing value preferences, value resonance should play a decisive role when looking at the effects of argument strength when it is contextualized by different value frames. When assessing the quality of issue-specific arguments, people tend toward motivated reasoning, i.e., new information is not processed unbiasedly with the goal of accurately judging this information, but new arguments are evaluated in the light of prior beliefs that can lead to a (dis-)conformation bias to maintain those pre-existing beliefs (Druckman \& Bolsen, 2011; Taber \& Lodge, 2006). This does not mean, however, that citizens always dismiss the quality of issue-specific arguments. When arguments are presented isolated, people tend to follow the stronger one regardless of the individual party preference (Druckman et al., 2013). In contrast, when arguments are presented with a party cue emphasizing the relevance of one's political identity, the strength of the argument loses its importance, and people follow the argument of the preferred party regardless of its strength, especially when the participant is told that parties are polarized on the topic (Druckman et al., 2013) or when the debate is about a conflict issue (Slothuus \& de Vreese, 2010). That is, citizens tend toward stronger motivated reasoning in situations in which their political identity is more salient and needs to be defended.

Like party preferences, political value preferences are an important aspect of citizens' political identity. When arguments are contextualized with a value-resonant frame that explicitly emphasizes the importance of interpreting the arguments with an identity-relevant frame, the strength of arguments should be evaluated more biasedly than in situations without a frame, where the relevance of the arguments for the person's identity is less salient. That is, whereas the presentation of new information with varying argument strength but without additional framing 
should be effective for attitude formation, the effect of the issue-specific argument strength should be suppressed by a value-resonant frame. This way, citizens should follow their frame to the same degree - regardless of whether this frame contextualizes new thematic information containing a weak or a strong argument for forming an attitude in the direction of the frame.

H5: Compared to situations without explicit framing, a value-resonant salience emphasis frame will suppress the effect of the argument strength of new thematic information.

To ensure that this suppression effect is not solely the result of distracting people from the issue-specific arguments by adding a frame, but that the suppression is the actual result of motivated reasoning increased by a value-resonant frame, one should not only investigate whether an argument loses its effectiveness when the frame is value-resonant compared to a situation without frames. In contrast, the argument effect should persist when only a counterframe is presented, implying that frames do not generally distract from the arguments, but that value resonance suppresses the effects of argument strength. Thus, the last hypothesis states:

H6: Compared to situations with an oppositional counter-frame, a value-resonant salience emphasis frame will suppress the effect of the argument strength of new thematic information.

\section{Method}

\section{Design and manipulation}

I conducted a randomized 2 (argument strength) x 3 (frame) x 2 (quasi-factor value preference) between-subjects online experiment in February 2018. In all conditions, participants had to read a news article containing the manipulations. The article dealt with a new therapy against bowel cancer and whether this therapy should receive approval from the politically responsible federal health ministry and be offered by mandatory basic health insurance. This move would increase insurance rates for all insured people in the country, making the topic 
personally relevant for the participants. In addition, the superordinate topic of health politics mirrors the classic political cleavage between economic-individualism and humanitarianism in social welfare (Feldman \& Steenbergen, 2001), which can be addressed by communicated frames. For a longer discussion on issue selection, see the supplementary method documentation SMD (Kaiser, 2019, pp. 5-11, available via https://doi.org/10.23662/FORS-DS-1013-1).

The article contained four parts: 1) a varying headline depending on the frame condition, 2) a constant neutral picture for the realism of the article, 3) an informational paragraph introducing new substantive information about the topic with varying argument strength but without any explicit frame contextualization, 4) and a framing paragraph with varying frames contextualizing the given information but without adding any new information about the therapy. Both paragraphs were of same length to avoid favoring either the framing or the argument effect.

The first factor varied the issue-specific argument strength against the approval of the therapy as being strong or weak in the informational paragraph. Depending on the condition, participants read either that the new therapy would be considerably more expensive, thereby increasing the yearly insurance rate by 300 francs per capita (strong argument against the approval), or that the new therapy would be only slightly more expensive than existing medicaments, leading to a small yearly increase in insurance rates of ten francs (weak argument). The counter-argument in favor of the approval was constant in all conditions mentioning that the new therapy is more effective than existing ones and would increase the probability of curation from $20 \%$ to $30 \%$ (for the exact wording of all conditions, see SMD, p. 16).

For the second factor, I manipulated the value frame in the framing paragraph that contextualized the given information on the topic without adding any new information about the issue. Since the approval of the new therapy is a social welfare measure dealing with direct 
assistance for the needy, I applied either an economic-individualism or a humanitarianism frame (Feldman \& Steenbergen, 2001; Shen \& Edwards, 2005). The economic-individualism frame contextualized the issue by highlighting the additional costs of the new but only slightly more effective therapy. Its main point was the well-known and cross-thematic interpretation that the therapy is a further example of threatening the financial stability of the social welfare system. In contrast, the humanitarianism frame employed the cross-thematic value of providing aid for the sick and the weak. In this view, societal solidarity is crucial and each new and more effective medical treatment should be available through the basic health insurance to ensure the best medical care for everyone. This factor also contained conditions without any explicit frame but solely with the substantive information regarding the therapy (i.e., the control groups).

The third factor was a quasi-factor obtained by dividing the sample after data collection into participants with a low or high preference for the political value of economic-individualism to generate (mis-)matches between the values of the participants and the value frames in the stimuli. As the issue-specific argument strength in the design varied only the information against the approval (i.e., the amount of additional costs), my analysis will focus solely on the corresponding frame economic-individualism that contextualized this new thematic information compared to the other framing conditions and how the frame interacts with the value preference.

\section{Sample and statistical power}

Using the online access panel of Respondi, I recruited an interlocked quota sample of inhabitants of the German-speaking part of Switzerland that was representative for gender and age between 18 and $69(n=833$, completion rate: $45.2 \%)$. There were $n=420$ women $(50.4 \%)$ and $n=413$ men (49.6\%) in the sample. The average age was $M=42.92(S D=14.41)$; the participants earned an average income of about CHF 75,000 (converts to about USD 76,000); 
and about half reported holding at least a high school degree $(n=440,53 \%)$.

I performed a power analysis to estimate an appropriate sample size. Given that $\mathrm{H} 5$ and H6 statistically propose three-way-interactions and that the diminishing effect of argument strength should not be an artifact of too low power, I opted for a rather strong statistical power with 1- $\beta$ of .85 for even small effect sizes $(d=.3)$. To ensure that the power won't decrease due to inevitable data cleansing, I defined a-priori seven criteria for adequate participation in the study (see SMD, p. 41-44). Participants who failed to meet any one of these criteria were screened out and could not finish the interview. All those who met these criteria and finished the interview were used for later data analysis without any further cleansing after data collection.

\section{Procedure and measures}

I received the consent of the participants, then measured their age, gender, residency, education, and income. Next, I asked some filler questions to distract the participants from the goal of the study before they saw the stimulus page with the described news article. Then, I asked for the dependent variable and treatment checks before the survey finished with additional distractor questions, questions on relevant control variables, and questions on the political value preference for economic-individualism (see SMD, pp. 36-41). By asking the value preference at the end, I avoided any priming of these values to not overestimate its influence by design.

Dependent variable. The issue attitude regarding the approval of the therapy was measured through three items using 6-point scales from 1 to 6 ("I believe approval of the new therapy is fully right," "In my opinion, the new therapy should definitely be approved," "I deem that the approval of the new therapy is completely appropriate"). The items showed high reliability $(\alpha=.97)$ and were summarized to an index $(M=4.28, S D=1.48)$.

Quasi-factor. I measured the value preference for economic-individualism with four 
items employing 6-point scales ("Our society should not risk its wealth by constantly spending money for aid to individuals," "Financial solidity is crucial for society and cannot be endangered by too-high welfare spending," "The financial costs must not be too high when society helps individuals," "A developed society implies that it has an eye on financial expenses instead of supporting individuals with money," $\alpha=.85, M=3.73, S D=1.13$ ).

Treatment checks. The perceived framing of the article was measured by a single item on a 7-point scale asking whether the shown article emphasized the costs (1) or the benefits (7) of the therapy $(M=3.94, S D=1.53)$. For the perceived quality of the article, I used five items ("professional," "realistic," "credible", "coherent", "well written") using 7-point scales and summarized to an index $(\alpha=.88, M=4.95, S D=1.16)$. The questionnaire contained some further successful treatment checks that can be found in the SMD (pp. 60-73).

Control variables. As the manipulation of the issue-specific argument strength dealt with numbers, I used the scale by Fagerlin et al. (2007) to measure cognitive numeracy abilities as a control along with political knowledge, political leaning and 13 further control variables that are documented in the SMD (pp. 30-35). The questionnaire also contained measures for further dependent variables and mediators of framing effects that are not in the focus of this article but are also reported in the SMD (pp. 23-26) including their results (pp. 110-126).

I performed a simultaneous confirmatory factor analysis with all measures consisting of more than one item using the MLR estimator revealing a good model fit $(\mathrm{CFI}=.963, \mathrm{TLI}=.960$, RMSEA $=.031$, SRMR $=.035$ ). Therefore, I predicted the factor scores for all these measures and used the latent variables for all analyses. Through this procedure, all these variables have a mean of zero. To allow meaningful interpretations while using the latent variables, I presented the original means and standard deviations above. In addition, I tested for the convergent validity 
of the economic-individualism scale by correlating it with the classic left-right scale showing a substantive correlation $(r=.46, p<.001, n=831)$. To follow the experimental logic, I split the variable using the median $(M d n=0.01$ of the latent variable equating to a value of 3.74 on the original 6-point scale, i.e., close to the midpoint of the scale of 3.5) into two equally big groups to employ this variable as a quasi-factor indicating low $(n=416,49.9 \%)$ or high $(n=417$, $50.1 \%$ ) value preference for economic-individualism. For the robustness check of the results, I will secure the findings beyond the median split by employing the metric latent variable as statistical quasi-factor. Both, the dichotomized variable $(p=.083)$ as well as the metric variable $(p=.117)$ were independent of the manipulations.

\section{Treatment and manipulation checks}

I also computed two treatment checks. A one-way Welch-test displayed that frame perception significantly differed between framing conditions $\left(F_{(2,551)}=55.86, p<.001, \eta^{2}=\right.$ 0.126). A post hoc test with Tukey's correction confirmed that articles with the economicindividualism frame $(M=3.21, S D=1.54)$ were perceived as focusing significantly more $(p<$ $.001, d=.89)$ on the costs of the therapy than articles with the humanitarianism frame $(M=4.51$, $S D=1.39)$ and articles without a frame $(M=4.12, S D=1.35)$ with $p<.001(d=.63)$. Likewise, the humanitarianism frame was perceived to focus significantly more $(p=.004, d=.28)$ on the benefits of the therapy than the articles without a frame. Regarding the perceived quality of the articles a one-way ANOVA confirmed that all three framing conditions did not differ significantly from each other $\left(F_{(2,830)}=1.38, p=.253, \eta^{2}=.003\right)$.

The most important prerequisite of the design was to ensure that the argument strength was manipulated correctly and showed effects on issue attitude. I tested this by comparing the two control groups without explicit frames but solely with the informational part with varying 
argument strength. A two-way ANOVA with the factors argument strength and value preference confirmed that the strong cost argument $(M=-0.09, S D=1.39)$ led to significantly lower $\left(F_{(1,278)}\right.$ $\left.=13.11, p<.001, \eta^{2}=.039\right)$ support for the approval of the therapy than the weak cost argument $(M=0.46, S D=1.20)$ over both value preferences without a significant interaction effect. It is likewise important that this effect on aggregate also persists when looking only at participants with a high preference for economic-individualism. This is because it should be secured that there is an argument effect for this group when no frames are present that later can be suppressed by a value-resonant frame. A simple effects analysis for the effect of argument strength by the single level of high value preference for economic-individualism revealed that the strong cost argument $(M=-0.39, S D=1.38)$ led to significantly $(p<.001)$ lower support for the therapy than the weak argument $(M=0.32, S D=1.21)$, again with a noticeable effect size $(d=.55)$.

\section{Results}

Given the categorical factors, I computed a saturated factorial between-subject ANOVA in R (the script and dataset can be retrieved from https://doi.org/10.23662/FORS-DS-1013-1) with the independent variables of issue-specific argument strength, salience emphasis frame, and value preference, and with issue attitude as the dependent variable. To allow meaningful interpretation of simple main effects proposed in the hypotheses $(\mathrm{H} 1-\mathrm{H} 4)$ while simultaneously testing interaction effects in the model (H5 and H6), I used sum-to-zero contrasts that do not test against the grand mean but against defined groups (Darlington \& Hayes, 2016). That is, weak and strong arguments were tested against each other in the model (H1); the frame economicindividualism was tested once against the no frame condition (H2) and once against the counterframe humanitarianism (H3); and low and high preference for economic-individualism were tested against each other $(\mathrm{H} 4)$. All these effects were controlled for all other main and interaction 
effects. The model explained $14.7 \%$ of the variance $\left(F_{(11,821)}=12.83, R^{2}=.147, R^{2}\right.$ adjusted $\left.=.135\right)$ and was significant with $p<.001$ (see Table 1 for the model and Figure 1 for a bar plot of individual group means; descriptive data are available in the SMD, p. 87).

\section{--- TABLE 1 AND FIGURE 1 ABOUT HERE ---}

The ANOVA displayed in Table 1 revealed four main effects. First, argument strength (H1) exerted a significant main effect on the dependent variable $\left(F_{(1,821)}=31.50, p<.001, \eta^{2}=\right.$ $.031)$ indicating that strong issue-specific arguments against the therapy $(M=-0.26, S D=1.51)$ led to lower support for the approval than weak arguments $(M=0.27, S D=1.33)$. Second, the ANOVA showed two significant main effects of the frame economic-individualism ( $\mathrm{H} 2$ and $\mathrm{H} 3)$. This frame $(M=-0.58, S D=1.53)$ significantly decreased support for approval $\left(\mathrm{H} 2, F_{(1,821)}=\right.$ 44.98, $\left.p<.001, \eta^{2}=.046\right)$ when compared to the no-frame condition $(M=0.18, S D=1.32)$ and significantly reduced support $\left(\mathrm{H} 3, F_{(1,821)}=64.81, p<.001, \eta^{2}=.067\right)$ when compared to the counter-frame of humanitarianism $(M=0.41, S D=1.30)$. Third, the general value preference for economic-individualism exerted a significant main effect $\left(\mathrm{H} 4, F_{(1,821)}=20.59, p<.001, \eta^{2}=\right.$ .022). A high preference for this value led to stronger disagreement with the approval $(M=-0.24$, $S D=1.48)$ compared to participants with a low preference for this value $(M=0.24, S D=1.38)$.

Furthermore, the ANOVA in Table 1 revealed no significant two-way interactions, indicating that the effect of the economic-individualism frame was not conditioned by the issuespecific argument strength it contextualized (RQ1) nor by citizens' political value preference for economic-individualism (RQ2). Moreover, a simple effects analysis using Tukey's correction revealed for RQ1 that the economic-individualism frame $(M=-0.76, S D=1.61)$ significantly reduced support compared to no frame $(M=-0.09, S D=1.39, p<.001, d=.45)$ and to the counter-frame humanitarianism $(M=0.10, S D=1.40, p<.001, d=.57)$ when the argument was 
strong but also when the argument was weak $\left(M_{\text {economic-individualism frame }}=-0.38, S D_{\text {economic-individualism }}\right.$ frame $=1.42, M_{\text {no frame }}=0.46, S D_{\text {no frame }}=1.20, M_{\text {humanitarianism frame }}=0.72, S D_{\text {humanitarianism frame }}=$ $1.11, p_{\text {economic-individualism vs. no frame }}<.001, d$ economic-individualism vs. no frame $=.64, p_{\text {economic-individualism vs. }}$ humanitarianism frame $<.001, d_{\text {economic-individualism vs. humanitarianism frame }}=.86$ ). For RQ2, results showed that the effect of the economic-individualism frame compared to no frame and the humanitarianism frame was significant for participants with a high preference for economic-individualism $\left(M_{\text {economic-individualism frame }}=-0.73, S D_{\text {economic-individualism frame }}=1.56, M_{\text {no frame }}=-0.04, S D_{\text {no frame }}=\right.$ $1.34, M_{\text {humanitarianism frame }}=0.12, S D_{\text {humanitarianism frame }}=1.39, p_{\text {economic-individualism vs. no frame }}<.001$, $d_{\text {economic-individualism vs. no frame }}=.48, p_{\text {economic-individualism vs. humanitarianism frame }}<.001, d_{\text {economic-individualism vs. }}$ humanitarianism frame $=.57)$ as well as with a low preference for this political value $\left(M_{\text {economic-individualism }}\right.$ frame $=-0.41, S D_{\text {economic-individualism frame }}=1.49, M_{\text {no frame }}=0.45, S D_{\text {no frame }}=1.26, M_{\text {humanitarianism frame }}$ $=0.62, S D_{\text {humanitarianism frame }}=1.19, p_{\text {economic-individualism vs. no frame }}<.001, d_{\text {economic-individualism vs. no frame }}=$ $\left..62, p_{\text {economic-individualism vs. humanitarianism frame }}<.001, d_{\text {economic-individualism vs. humanitarianism frame }}=.77\right)$.

As the first three-way interaction in Table 1 shows, the proposed suppression of the effect of argument strength when the economic-individualism frame was value-resonant compared to situations without frames (H5) was not significant $\left(F_{(1,821)}=1.37, p=.242, \eta^{2}=.001\right)$. Nevertheless, a deeper look at the interaction plot with simple effects supported H5 (see Figure 2). The left panel displays that argument strength did not have an effect when the economicindividualism frame was value-resonant $\left(M_{\text {weak argument }}=-0.57, S D_{\text {weak argument }}=1.40, M_{\text {strong argument }}\right.$ $\left.=-0.87, S D_{\text {strong argument }}=1.68, p=.17 d=.20\right)$ whereas arguments had a significant effect without frames for participants with a high preference for economic-individualism $\left(M_{\text {weak argument }}\right.$ $\left.=0.32, S D_{\text {weak argument }}=1.21, M_{\text {strong argument }}=-0.39, S D_{\text {strong argument }}=1.38, p=.001, d=.55\right)$.

In addition, the second three-way-interaction in Table 1 for the suppression of the effects 
of argument strength was significant $\left(F_{(1,821)}=4.13, p=.043, \eta^{2}=.004\right)$ when the economicindividualism frame was value-resonant compared to situations with the non-resonant counterframe humanitarianism (H6). A simple effects analysis revealed that argument strength exerted a significant stronger effect on issue attitude when the counter-frame humanitarianism was presented for participants with a high preference for economic-individualism $\left(M_{\text {weak argument }}=\right.$ $0.67, S D_{\text {weak argument }}=1.13, M_{\text {strong argument }}=-0.40, S D_{\text {strong argument }}=1.42, p<.001, d=.83$ ) compared to the value-resonant frame where the effect of argument strength was non-significant. --- FIGURE 2 ABOUT HERE ---

To confirm these findings, I computed a row of additional ANCOVAs as robustness checks that 1) included all control variables, 2) used the metric variable for value preference instead of the split variable as a quasi-factor, and 3) employed a slightly different measurement model. The results of these models were quasi-identical to the first model displaying the same significant main effects. In addition, the proposed three-way-interaction for the suppressed effect of the argument strength when the economic-individualism frame was value-resonant compared to the situation with a non-resonant frame (H6) was even more significant, ranging between $p=$ .004 and $p=.038$ with eta squared between $\eta^{2}=.005$ and $\eta^{2}=.010$.

\section{Discussion}

These results suggest that salience emphasis frames can exert rather strong effects on issue attitudes even if these frames do not contain any new information about a policy but only contextualize given information and explain what this information means in the light of a wellknown and cross-thematic political value. The economic-individualism frame reduced citizens' support for approval of a new and more expensive therapy for the health system compared to situations without a frame and only new substantive information about the (dis-)advantages of 
the therapy $(\mathrm{H} 2)$ as well as compared to situations with a counter-frame contextualizing the same new thematic information with the value humanitarianism (H3). The effect of the economicindividualism frame was so strong that it could effectively move the issue attitude not only when the substantive information contained a high argument strength for opposing the approval but also when the thematic facts were only weakly compelling for such an attitude (RQ1). These results suggest that salience emphasis frames affect issue attitudes, and it is not solely the new issue-specific information that shapes attitudes as argued by recent critiques on emphasis framing (Leeper \& Slothuus, 2017; Scheufele \& Iyengar, 2017). This supports the concept of salience emphasis frames as a unique type of framing that can be distinguished theoretically and empirically from both narrow equivalency framing and confounded emphasis framing.

The results also shed light on the importance of citizens' political value preferences for framing effects. First, such value preferences influenced issue attitudes directly (H4). Regardless of argument strength or frames, citizens preferring the value of economic-individualism showed significantly lower support for treatment approval compared to citizens with a low preference for that value. This underlines the general relevance of superordinate political values on which people rely when forming attitudes on specific political topics (Ciuk et al., 2017; Jacoby, 2006).

Second, when citizens' value preference for economic-individualism matched the offered frame of the article, i.e., when the salience emphasis frame was value-resonant, this suppressed the effect of issue-specific argument strength that was otherwise present when there was no frame (H5) or a non-resonant counter-frame (H6). This suggests that value resonance can lead to strong forms of biased processing and motivated reasoning (Taber \& Lodge, 2006) in which the issue-specific facts for one's own side's frame are completely ignored. In fact, whereas the weak argument mitigates to simply follow pre-existing values when no frame or a counter-frame is 
present (i.e., citizens follow argument strength of thematic information in a less biased manner), this changes dramatically when the weak argument is contextualized with a matching economicindividualism frame. The weak argument is then as effective as a strong one and citizens follow their frame no matter if there are good reasons not to do so, such as having the same factual information they would agree to in non-resonant situations. This suppression effect implies that value resonance has comparable effects to party cues that foster motivated reasoning and also lead to a biased perception of the quality of issue-specific arguments (Druckman et al., 2013).

Third, the economic-individualism frame also influenced citizens with a low preference for economic-individualism (RQ2). This suggests that salience emphasis frames can also influence the opposite camp and do not solely persuade citizens with matching values. This strengthens the conclusion that such framing can be effective because it uses well-known political value frames that are in the stock of cultural frames (Entman, 1993), i.e., it applies available and applicable considerations (Chong \& Druckman, 2007c) even for citizens with nonmatching values. However, the suppression of the effect of issue-specific argument strength depended on a value-resonant frame and not occurred when the economic-individualism frame was non-resonant (see Figure 2) implying that non-resonant frames merely biased the evaluation of issue-specific argument strength, whereas value resonance fully suppressed its effects.

These results suggest that salience emphasis framing poses a risk to citizens' rationality in attitude formation. Such frames can lead to attitudes that are not substantiated by any changes in the thematic information but are solely the result of the salience of certain cross-thematic patterns of interpretation citizens already know. Moreover, if citizens are only exposed to their value-resonant frames, the influence of thematic facts can be very limited. This could complicate rational public discourses about political issues and could polarize citizens with different 
political orientations, especially when these citizens only expose themselves to their valueresonant frames and thus can no longer agree on the factual basis of political issues.

However, these interpretations have limitations. First, even if the informational part contained issue-specific arguments for both sides, each participant received only one frame contextualizing the information, i.e., the framing conditions were one-sided. Studies suggest that frames are less effective in two-sided and equally strong framing situations (Chong \& Druckman, 2007a; Druckman et al., 2013). Second, I only assumed that citizens already knew the cross-thematic patterns of interpretations employed as salience emphasis frames because economic-individualism and humanitarianism seem to be fundamental political values citizens should know (Feldman \& Steenbergen, 2001; Shen \& Edwards, 2005). However, when future research works with salience emphasis frames, it should test this assumption more thoroughly. Third, I chose a rather specific topic for the experiment which allowed me to manipulate the thematic argument strength in a way that the frames could rely on this information (see SMD, pp. 5-11). Fourth, I carefully selected the strength of both issue-specific arguments to avoid ceiling effects by creating them effective enough to exert effects on issue attitude but not too effective that the additional economic-individualism frame could still have an influence. This had the disadvantage that the counter-frame humanitarianism could not exert effects on top of the already strong argument of a high probability of curation (see SMD, p. 91). Hence, the results should not be interpreted that value-resonant salience emphasis frames always exert strong effects that suppress the effect of thematic information. Instead, results should be read as a proof of theory that frames can have such effects. However, I believe that there are more topics and issue-specific argumentative constellations where such frames can have these effects (e.g., public safety measures with varying impacts on security and civil rights; infrastructure projects with 
varying impacts on the economy and the environment), which future research could examine.

Despite these limitations, this study showed that salience emphasis framing can affect political issue attitudes even if the frame does not provide any new information about the topic and only contextualizes the given information by applying a known political value. When frames match citizens' value preferences, citizens can completely ignore the quality of the issue-specific arguments they react to when there is no frame or a counter-frame. That is, value resonance can lead to a (more) biased perception of politically relevant thematic information. From a normative perspective, this leads to the question of whether and how the prerequisite of rational attitude formation for a functioning and not too polarized democracy can be fulfilled, if framing prevents a critical evaluation of the strength of the thematic facts and arguments of one's own side. 


\section{References}

Andrews, A. C., Clawson, R. A., Gramig, B. M., \& Raymond, L. (2017). Finding the right value: Framing effects on domain experts. Political Psychology, 38(2), 261-278. https://doi.org/10.1111/pops. 12339

Beattie, P., \& Milojevich, J. (2017). A test of the "news diversity" standard: Single frames, multiple frames, and values regarding the Ukraine conflict. The International Journal of Press/Politics, 22(1), 3-22. https://doi.org/10.1177/1940161216673194

Borah, P. (2011). Conceptual issues in framing theory: A systematic examination of a decade's literature. Journal of Communication, 61(2), 246-263. https://doi.org/10.1111/j.14602466.2011.01539.x

Cacciatore, M. A., Scheufele, D. A., \& Iyengar, S. (2016). The end of framing as we know it ... and the future of media effects. Mass Communication and Society, 19(1), 7-23. https://doi.org/10.1080/15205436.2015.1068811

Chong, D., \& Druckman, J. N. (2007a). Framing public opinion in competitive democracies. American Political Science Review, 101(4), 637-655. https://doi.org/10.1017/S0003055407070554

Chong, D., \& Druckman, J. N. (2007b). Framing theory. Annual Review of Political Science, 10(1), 103-126. https://doi.org/10.1146/annurev.polisci.10.072805.103054

Chong, D., \& Druckman, J. N. (2007c). A theory of framing and opinion formation in competitive elite environments. Journal of Communication, 57(1), 99-118. https://doi.org/10.1111/j.1460-2466.2006.00331.x

Ciuk, D. J., Lupton, R. N., \& Thornton, J. R. (2017). Values voters: The conditional effect of income on the relationship between core values and political attitudes and behavior. Political Psychology, 57(1), 176. https://doi.org/10.1111/pops.12442

Darlington, R. B., \& Hayes, A. F. (2016). Regression analysis and linear models: Concepts, applications, and implementation. New York: Guilford Press.

Druckman, J. N. (2001). The implications of framing effects for citizen competence. Political Behavior, 23(3), 225-256. https://doi.org/10.1023/A:1015006907312

Druckman, J. N., \& Bolsen, T. (2011). Framing, motivated reasoning, and opinions about emergent technologies. Journal of Communication, 61(4), 659-688. https://doi.org/10.1111/j.1460-2466.2011.01562.x

Druckman, J. N., Peterson, E., \& Slothuus, R. (2013). How elite partisan polarization affects public opinion formation. American Political Science Review, 107(1), 57-79. https://doi.org/10.1017/S0003055412000500 
Entman, R. M. (1993). Framing: Toward clarification of a fractured paradigm. Journal of Communication, 43(4), 51-58. https://doi.org/10.1111/j.1460-2466.1993.tb01304.x

Fagerlin, A., Zikmund-Fisher, B. J., Ubel, P. A., Jankovic, A., Derry, H. A., \& Smith, D. M. (2007). Measuring numeracy without a math test: Development of the subjective numeracy scale. Medical Decision Making, 27(5), 672-680. https://doi.org/10.1177/0272989X07304449

Feldman, S. (1988). Structure and consistency in public opinion: The role of core beliefs and values. American Journal of Political Science, 32(2), 416-440.

https://doi.org/10.2307/2111130

Feldman, S., \& Steenbergen, M. R. (2001). The humanitarian foundation of public support for social welfare. American Journal of Political Science, 45(3), 658. https://doi.org/10.2307/2669244

Hänggli, R., \& Kriesi, H. (2010). Political framing strategies and their impact on media framing in a Swiss direct-democratic campaign. Political Communication, 27(2), 141-157. https://doi.org/10.1080/10584600903501484

Jacoby, W. G. (2006). Value choices and American public opinion. American Journal of Political Science, 50(3), 706-723. https://doi.org/10.1111/j.1540-5907.2006.00211.x

Kaiser, J. (2019). Emphasis framing effects in political communication: Disentangling the effects of thematic information and emphasis frames and the suppression of issue-specific argument effects through value-resonant framing [Dataset and project documentation]. Lausanne: FORSbase. https://doi.org/10.23662/FORS-DS-1013-1

Kaiser, J., \& Kleinen-von Königslöw, K. (2019). Partisan journalism and the issue framing of the Euro crisis: Comparing political parallelism of German and Spanish online news. Journalism, 20(2), 331-348. https://doi.org/10.1177/1464884916683548

Lecheler, S. K., \& de Vreese, C. H. (2011). Getting real: The duration of framing effects. Journal of Communication, 61(5), 959-983. https://doi.org/10.1111/j.14602466.2011.01580.x

Lecheler, S. K., \& de Vreese, C. H. (2013). What a difference a day makes?: The effects of repetitive and competitive news framing over time. Communication Research, 40(2), 147175. https://doi.org/10.1177/0093650212470688

Leeper, T. J., \& Slothuus, R. (2017). Can citizens be framed? How information more than emphasis changes opinions. Retrieved from https://s3.us-east-2.amazonaws.com/tjlsharing/assets/CanCitizensBeFramed.pdf

Matthes, J., \& Schemer, C. (2012). Diachronic framing effects in competitive opinion environments. Political Communication, 29(3), 319-339.

https://doi.org/10.1080/10584609.2012.694985 
Nelson, T. E., Oxley, Z. M., \& Clawson, R. A. (1997). Toward a psychology of framing effects. Political Behavior, 19(3), 221-246. https://doi.org/10.1023/A:1024834831093

Neuman, W. R., \& Guggenheim, L. (2011). The evolution of media effects theory: A six-stage model of cumulative research. Communication Theory, 21(2), 169-196. https://doi.org/10.1111/j.1468-2885.2011.01381.x

Park, H. S., Levine, T. R., Kingsley Westerman, C. Y., Orfgen, T., \& Foregger, S. (2007). The effects of argument quality and involvement type on attitude formation and attitude change: A test of dual-process and social judgment predictions. Human Communication Research, 33(1), 81-102. https://doi.org/10.1111/j.1468-2958.2007.00290.x

Petty, R. E., \& Cacioppo, J. T. (1986). The elaboration likelihood model of persuasion. In L. Berkowitz (Ed.), Advances in experimental social psychology (pp. 123-205). Orlando, FL: Academic Press.

Schemer, C., Wirth, W., \& Matthes, J. (2012). Value resonance and value framing effects on voting intentions in direct-democratic campaigns. American Behavioral Scientist, 56(3), 334352. https://doi.org/10.1177/0002764211426329

Scheufele, D. A., \& Iyengar, S. (2017). The state of framing research: A call for new directions. In K. Kenski \& K. Hall Jamieson (Eds.), The Oxford handbook of political communication (pp. 619-632). Oxford: Oxford University Press.

Shen, F., \& Edwards, H. (2005). Economic individualism, humanitarianism, and welfare reform: A value-based account of framing effects. Journal of Communication, 55(4), 795-809. https://doi.org/10.1111/j.1460-2466.2005.tb03023.x

Slothuus, R. (2008). More than weighting cognitive importance: A dual-process model of issue framing effects. Political Psychology, 29(1), 1-28. https://doi.org/10.1111/j.14679221.2007.00610.x

Slothuus, R., \& de Vreese, C. H. (2010). Political parties, motivated reasoning, and issue framing effects. The Journal of Politics, 72(3), 630-645. https://doi.org/10.1017/S002238161000006X

Taber, C. S., \& Lodge, M. (2006). Motivated skepticism in the evaluation of political beliefs. American Journal of Political Science, 50(3), 755-769. https://doi.org/10.1111/j.15405907.2006.00214.x

Tversky, A., \& Kahneman, D. (1981). The framing of decisions and the psychology of choice. Science, 211(4481), 453-458. https://doi.org/10.1126/science.7455683 
Table 1. ANOVA Test of Between-Subjects Effects for Argument Strength, Frames, Value Preference (dichotomized), and Their Interactions on Issue Attitude

\begin{tabular}{|c|c|c|c|c|}
\hline Factor & $d f$ & $F$ & $\eta^{2}$ & $p$ \\
\hline Adjusted model & 11 & 12.83 & .147 & $<.001 * * *$ \\
\hline Argument strength & 1 & 31.50 & .031 & $<.001 * * *$ \\
\hline Frame economic-individualism vs. no frame & 1 & 44.98 & .046 & $<.001 * * *$ \\
\hline $\begin{array}{l}\text { Frame economic-individualism vs. } \\
\text { humanitarianism }\end{array}$ & 1 & 64.81 & .067 & $<.001 * * *$ \\
\hline Value preference for economic-individualism & 1 & 20.59 & .022 & $<.001 * * *$ \\
\hline $\begin{array}{l}\text { Argument strength } \mathrm{X} \text { frame economic- } \\
\text { individualism vs. no frame }\end{array}$ & 1 & 0.36 & $<.001$ & .549 \\
\hline $\begin{array}{l}\text { Argument strength } \mathrm{X} \text { frame economic- } \\
\text { individualism vs. humanitarianism }\end{array}$ & 1 & 1.54 & .001 & .215 \\
\hline $\begin{array}{l}\text { Argument strength } \mathrm{X} \text { value preference for } \\
\text { economic-individualism }\end{array}$ & 1 & 3.05 & .003 & .081 \\
\hline $\begin{array}{l}\text { Frame economic-individualism vs. no frame } \mathrm{X} \\
\text { value preference for economic-individualism }\end{array}$ & 1 & 0.48 & $<.001$ & .486 \\
\hline $\begin{array}{l}\text { Frame economic-individualism vs. } \\
\text { humanitarianism } \mathrm{X} \text { value preference for } \\
\text { economic-individualism }\end{array}$ & 1 & 0.50 & $<.001$ & .482 \\
\hline $\begin{array}{l}\text { Argument strength } \mathrm{X} \text { frame economic- } \\
\text { individualism vs. no frame } \mathrm{X} \text { value preference } \\
\text { for economic-individualism }\end{array}$ & 1 & 1.37 & .001 & .242 \\
\hline $\begin{array}{l}\text { Argument strength } \mathrm{X} \text { frame economic- } \\
\text { individualism vs. humanitarianism } \mathrm{X} \text { value } \\
\text { preference for economic-individualism }\end{array}$ & 1 & 4.13 & .004 & $.043 *$ \\
\hline
\end{tabular}

Note. $R^{2}=.147, R^{2}$ adjusted $=.135, * p<.05, * * * p<.001, n=833$ 


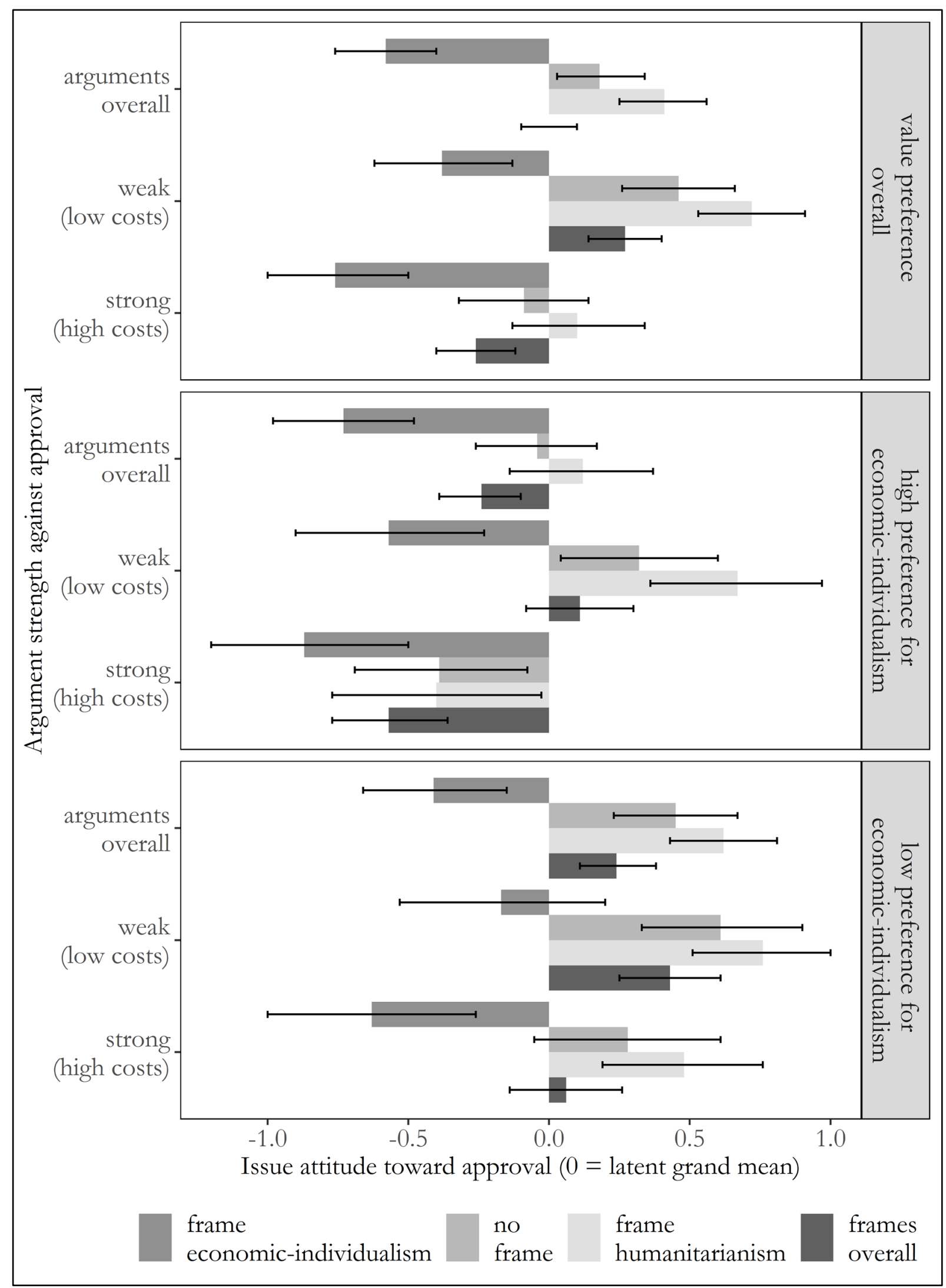

Figure 1. Individual group and factor means with 95\% confidence intervals using 5,000 bootstrap samples, $n=833$ 


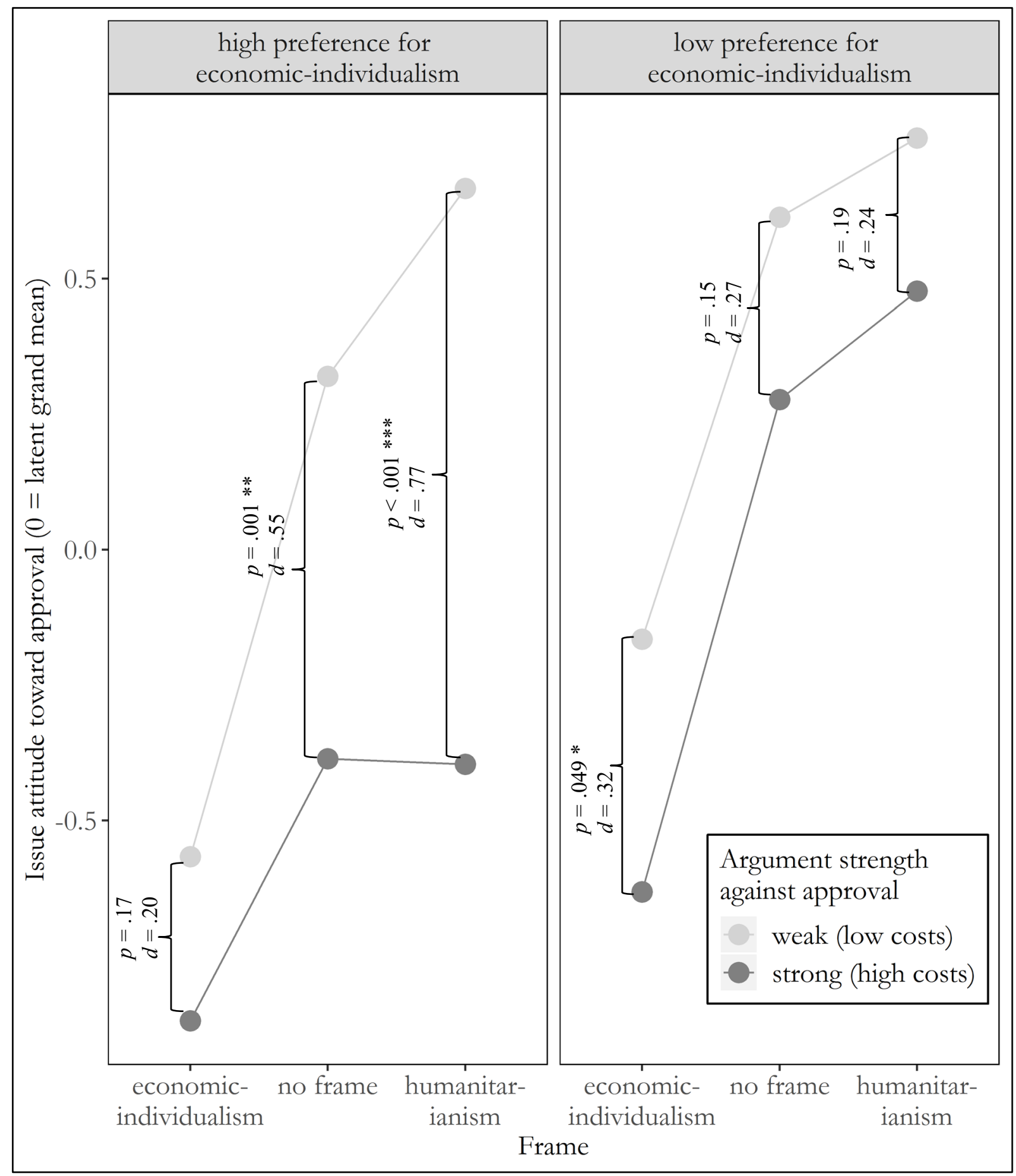

Figure 2. Effects of issue-specific argument strength by frames and political value preference, $* p<.05, * * p<.01, * * * p<.001, n=833$ 